\title{
Desenvolvimento moral em formandos de um curso de odontologia: uma avaliação construtivista
}

\author{
M oral development of graduates from an dentistry \\ course: a constructivist evaluation
}

\author{
Sérgio Fernando Torres de Freitas 1 \\ Douglas Francisco Kovaleski 1 \\ Antonio Fernando Boing 1
}

1 Departamento de Saúde Pública, Centro de Ciências da Saúde, UFSC. Campus Universitário, Trindade, 88010-970, Florianópolis SC.

torresdefreitas@terra.com.br
Abstract A debate is conducted on the moral de velopment of graduates from an odontology course, based on a constructivist model. A problem was offered to the students, asking for the solution of a morally based dilemma. By means of interviews, it was possible to qualify the students in one of the five levels of moral development. $M$ ain results showed that: a) about $66 \%$ of graduates fit the first two stages of moral development. At this level, there is no capacity to make situations and moral dilemmas relative, or solution is found within a logic of personal interest; $b$ ) just a little less than $10 \%$ of the subjects acknowledged that moral norms and values can be made relative, to be oriented towards attaining a common good; c) law values were preferred to those of life, for the majority of subjects; d) the ensemble of values by which the choice of dilemma was guided was in greater part defined by utilitarian and individualistic consequences, and by the search for rewards and the concern with one's reputation. Discussed next are the potential consequences this moral development profile has upon dentistry, the ethic relations of the quotidian upon professional practice, and the little capacity courses have to solve this problem, seen as fundamental to rearrange the profile of human resources necessary to the country: dentists with good technical capacity and social responsibility.

Key words O dontology teaching, M oral development, $\mathrm{H}$ ealth education
Resumo 0 desenvolvimento moral de formandos de um curso de odontologia foi analisado a partir de um modelo construtivista. Foi apresentado aos alunos um dilema de fundo moral a ser resolvido. Por meio de entrevistas, estabeleceu-se a qualificação dos alunos em um dos cinco níveis de desenvolvimento moral. Os resultados mostram que: a) $66 \%$ dos formandos estão nos dois primeiros estágios de desenvolvimento moral, onde não há capacidade de relativizar situações e dilemas morais, ou estes são resolvidos na lógica de interesse pessoal; b) o reconhecimento de que normas e valores morais podem ser relativizados e devem ser orientados para o bem comum foi atingido por menos de $10 \%$ dos entrevistados; $\mathrm{c}$ ) os valores de lei prevaleceram aos de vida para a maioria; d) o conjunto de valores que orientou a escol ha do dilema foi majoritariamente definido pela busca de recompensa e a preocupação com a própria reputação. Foram discutidas as potenciais conseqüências deste perfil de desenvolvimento moral sobre a odontologia, as relações éticas do cotidiano da prática profissional, ea incapacidade dos cursos em resolver este problema, considerado fundamental para uma reorientação do perfil de recursos humanos necessário ao País: 0 de um dentista com boa capacidade técnica e responsabilidade social.

Palavras-chave Ensino odontológico, D esenvolvimento moral, Educação em saúde 


\section{Introdução}

A formação odontológica brasileira tem sido sistematicamente criticada por seu caráter excessivamente técnico. Algumas dessas críticas se transformaram em trabal hos clássicos para a área, como o de $M$ endes \& M arcos (1985), ao propor um novo modelo de ensino e prática, a O dontologia Integral. N o mesmo período, os diversos trabalhos de Cordón $(1977,1980,1982)$ sobre a necessidade de simplificação e desmonopolização do saber e práticas odontológicas, entre outros, firmaram a concepção de que o ensino odontológico peca por excesso de tecnicismo em detrimento de aspectos fundamentais, como a prevenção, uma relação pacienteprofissional mais humanizada e a própria ética do cotidiano.

U m reflexo desta preocupação pode ser visto com clareza no estabelecimento do currículo mínimo vigente entre 1982 e a promulgação da nova Lei de Diretrizes e Bases da Educação (LDB), em 1998. 0 perfil desejado é o de um profissional "tecnicamente capaz e socialmente sensível". Embora existam al guns trabalhos que dêem respal do à necessidade de se conseguir formar este profissional, não há muita discussão ou clareza sobre o que seria e como se produz esse dentista socialmente sensível.

O trabalho de Paixão (1981) "O paciente como objeto de ensino" dá uma boa medida do tipo de problema e das distorções inerentes à formação odontológica brasileira, situação essa que se mantém até os dias de hoje, pois na grande maioria dos cursos ainda há seleção de pacientes para tratamento cujo critério é o chamado "interesse acadêmico".

N este sentido, a idéia dos conteúdos transversais - conteúdos fundamentais de ensino que não estão incluídos em nenhuma área concreta do currículo, nem definem etapas, mas que se estendem por todo o ciclo de formação - comum à área de educação, mas ignorada na maioria dos cursos de odontologia no Brasil, ganha um caráter estratégico essencial.

A partir desse conceito, o respeito à ética, nas relações com professores, colegas e principalmente com pacientes, passa a ser apreendido nas relações cotidianas de ensino, na prática de todos os envolvidos e com a discussão destas relações de modo a que o futuro dentista tenha estes conceitos profundamente arraigados.

Este trabal ho busca uma primeira aproximação para se trabalhar com a educação de valores morais, sob o eixo dos direitos humanos.
Está baseado na obra de Aguado \& M edrano (1999), que adota a concepção construtivista de explicação do desenvolvimento moral, em que princípios universais de critérios de juízo, como solidariedade, igualdade, respeito, etc. são melhores que princípios convencionais, baseados em padrões culturais ou de posição social para a resolução de conflitos e relações pessoais. 0 trabalho destas autoras está fundamentado nas teorias de Kohlberg (1958, 1984, 1999), que vem desenvolvendo o tema nos últimos trinta anos, bem como de Piaget (1972).

Assim, o objetivo básico é identificar, a partir da metodologia proposta, em que níveis de desenvolvimento moral estão os futuros dentistas. Ou seja, em que níveis de aplicação de valores morais universais trabal ham os estudantes de odontologia diante de um problema concreto. U ma discussão sobre as possíveis conseqüências desta situação para a ética cotidiana também é sugerida, tendo como pano de fundo a tentativa de formação desse profissional mais humano e sensível, ainda desejado pela profissão.

\section{Metodologia}

A partir do trabalho de Aguado \& M edrano (1999), que apresentam um mecanismo de avaliação do desenvolvimento ético e moral em escolares, foi aplicado um plano de entrevista para avaliação desses níveis, em formandos de um curso de odontologia. Estes foram colocados diante de um dilema hipotético e, a partir dele, foi feita uma série de perguntas aos entrevistados.

A) Caracterização do estudo. Para avaliar o nível de desenvolvimento ético e moral, a bibliografia propõe alguns dilemas com várias situações em que aparecem valores em conflito. Dentre eles optou-se pelo dilema vida/lei, por ser este o que trabal ha valores mais próximos da futura prática profissional dos alunos. Durante as duas últimas semanas de aula foram entrevistados 42 formandos, de ambos os sexos, com idades entre 22 e 28 anos, de uma turma de 56 alunos, voluntários esclarecidos sobre os objetivos do trabalho. Os demais não foram atingidos devido à indisponibilidade de tempo ou negativa em participar da pesquisa. Antes da entrevista foi feito um pré-teste do mecanismo de coleta de dados em estudantes da fase imediatamente anterior. As entrevistas do pré-teste foram aplicadas com e sem uso de gravador. Concluiu-se 
que o gravador era dispensável por não proporcionar acréscimo relevante em riqueza de detalhes, optando-se, então, pela anotação direta dos dados.

B) Apresentação do problema. A seguinte situação foi apresentada aos entrevistados, para leitura direta, de modo que não houvesse qualquer influência por parte do entrevistador:

$\mathrm{Na}$ Europa, uma mulher estava a ponto de morrer de um tipo de câncer muito especial. Havia um medicamento que, segundo os médicos, poderia salvá-la. Era um tipo de remédio que 0 farmacêutico da mesma cidade havia descoberto recentemente. 0 medicamento era caro para ser produzido, mas o farmacêutico cobrava dez vezes mais do que Ihe havia custado elaborá-lo. Ele pagou duzentos reais, mas cobrava dois mil por uma pequena dose. $\mathrm{O}$ marido da enferma, $\mathrm{H}$ enrique, recorreu a todo o mundo que conhecia para pedir o dinheiro emprestado, e tentou todos os meios legais, mas só pôde conseguir mil reais, a metade do que custava. H enrique disse ao farmacêutico que sua mulher estava morrendo e pediu que lhe ven desse o remédio mais barato ou que lhe dei xasse pagar mais adiante. Entretanto o farmacêutico disse. "Não, eu descobri o medicamento e tenho que ganhar dinheiro com ele". Então, $\mathrm{H}$ enrique entrou desesperado na farmácia e roubou o remédio para sua mulher.

Em seguida, foram feitas as perguntas:

1. Devia Henrique roubar o remédio? 1a. Por que sim ou por que não?

2. (A pergunta 2 é elaborada para conhecer o tipo de moral do sujeito e é opcional). É bom ou mau que ele roube o remédio? 2a. Por que ébom ou mau?

3. Henrique tem o dever ou a obrigação de roubar o remédio? 3a. Por que sim ou por que não?

4. Se Henrique não quisesse bem sua mulher, deveria roubar o remédio? Se o sujeito é a favor de não roubar, perguntar: Existe alguma diferença com respeito ao que deve $\mathrm{H}$ enrique fazer se quer bem sua mulher ou se não quer?

5. Imagine que a pessoa que está morrendo não fosse sua mulher, mas um estranho; deveria H enrique roubar o remédio para um estranho? 5a. Por que sim ou por que não? (Se o sujeito é a favor de roubar o remédio para um desconhecido)

6. Imagine que é um animal que quer muito bem; deveria $\mathrm{H}$ enrique roubar para salvar a vida de um animal? 6a. Por que sim ou por que não? 7. É importante fazer todo o possível para salvar outra vida? 7a. Por que sim ou por que não? 8. Está $\mathrm{H}$ enrique contrário à lei por roubar 0 remédio? 8a. Por que sim ou por que não?
9. Deve se fazer todo o possível para obedecer à lei? 9a. Por que sim ou por que não?

Em suas respostas, o entrevistado deveria optar por um dos valores (vida ou lei), sendo tencionado a explicar sua posição e seu modo de pensar e agir. A partir dessa opção e pela capacidade de sustentar sua posição é possível analisar o desenvolvimento ético e moral do entrevistado. 0 fluxograma representado na figura 1 descreve sucintamente os passos do instrumento até a classificação final de cada entrevistado.

C) Análise das respostas. 0 conteúdo do dilema exposto divide-se nas categorias valores, normas e elementos (ou critério de juízo). A interação destas categorias irá qualificar o entrevistado em um estágio determinado. Para a correta análise do estágio é necessário avaliar as explicações do aluno para a sua escolha por determinado dilema. Daí a importância do entrevistado sustentar e argumentar a favor desta escolha.

Temos, portanto, o conteúdo da entrevista dividido nessas três categorias (valores, normas e elementos) para avaliação dos estágios e subestágios. Este é importante para definição da existência ou não de coerência entre raciocínio e ação moral por parte do entrevistado. 0 subestágio $\mathrm{B}$ assume maior maturidade de raciocínio e apresenta características de respeito mútuo, autonomia e reversibilidade. Já o subestágio A, caracteriza-se fortemente por uma orientação heterônoma, demonstrando pouca coerência nas respostas do entrevistado.

Inicialmente foi observado para qual valor - vida ou lei - o sujeito se inclinava. Caso ele não optasse por nenhum, era tencionado a se posicionar. Quando mudava de valor durante as respostas, considerou-se o último escolhido.

A partir do valor assumido, ele teve de explicar sua posição e defendêla através de argumentações, configurando as normas. Baseado nelas o sujeito sustenta sua opção. Essas normas classificam-se como apresentadas no quadro 1.

Já os elementos configuram-se como as motivações éticas que guiaram a justificativa das respostas do sujeito e se referem mais à estrutura do raciocínio (Quadro 2).

Após as entrevistas, as respostas foram classificadas, sendo definidos os valores (vida ou lei) de opção dos entrevistados e os subestágios A ou B. Para cada valor foram identificados as normas e os elementos, que formam um critério de juízo, ou CJ. Embora a técnica adotada no trabalho permita uma pontuação quantitativa, 
Figura 1

Fluxograma de coleta e definição do estágio de desenvolvimento moral.

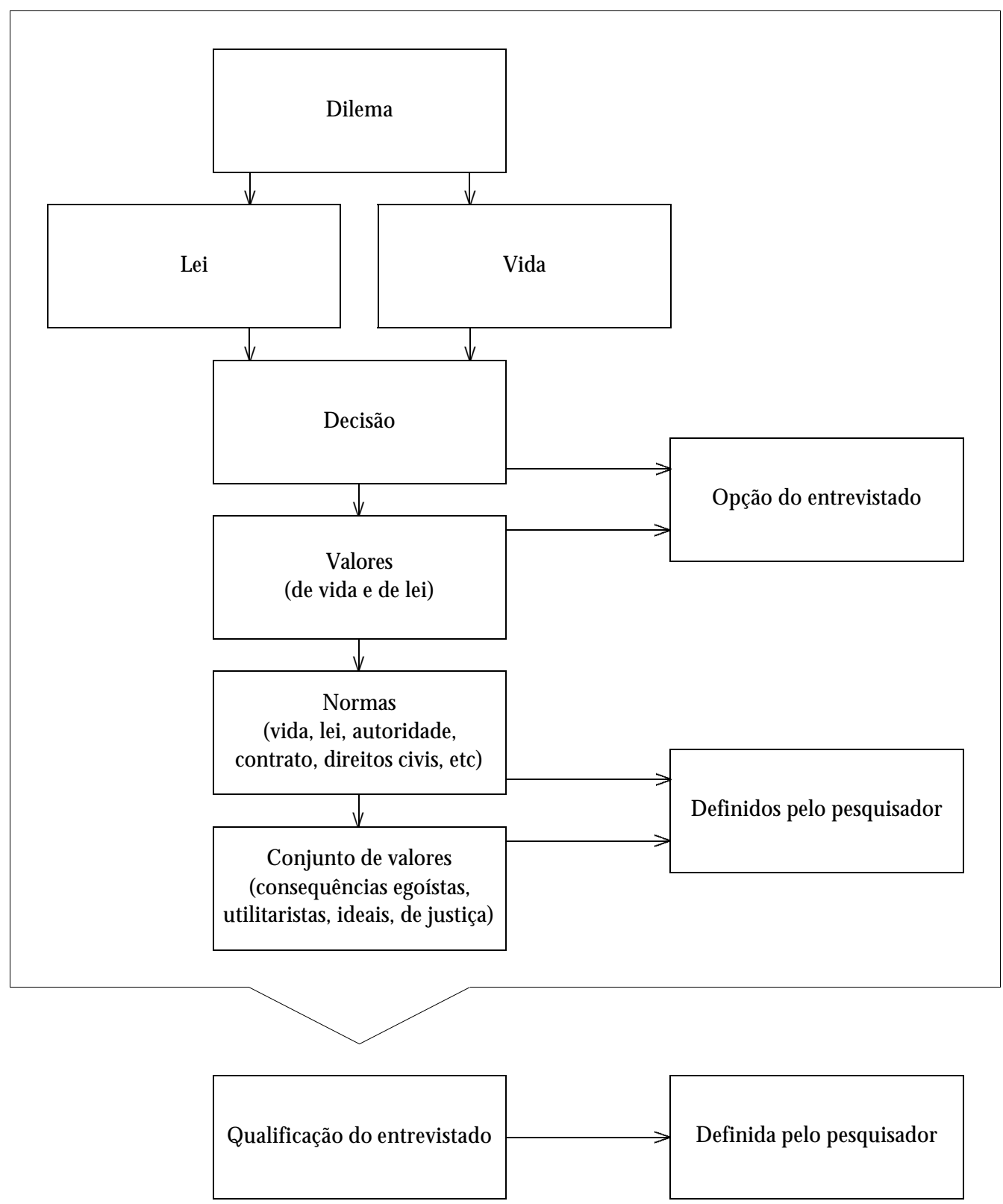


optou-se por uma análise exclusivamente qualitativa, por meio das decisões assumidas pelos entrevistados. Então os alunos foram classificados em um dos cinco estágios de desenvolvimento moral, descritos a seguir.

O ESTÁGIO 1 caracteriza-se pela unilateralidade. D efine justiça em função de poder e status. Regras morais são aplicadas de forma absoluta e/ou literal, sem levar em conta as circunstâncias, pois é incapaz de diferenciar perspectivas. O ESTÁGIO 2 apresenta conflitos resolvidos através de intercâmbios diretos, tratando os interesses do indivíduo de forma indiferenciada, sem relativizar contextos ou situações. Com uma reciprocidade simples e concreta conta também com orientação individualista e hedonista. Já o EST ÁGIO 3 adota a perspectiva de uma terceira pessoa, superando 0 individual ismo instrumental, assumindo um conjunto de normas compartilhadas. Caminha no sentido de "faça com os outros o que gostaria que fizessem contigo". O ESTÁ GI 04 adota a perspectiva de um membro da sociedade, em que um sistema social tem procedimentos que se aplicam imparcialmente a todos. Aqui, deveres e direi tos têm de ser correlativos, relativizados em função da situação em que ocorrem. 0 ESTÁGIO 5 julga a validade das leis e sistemas sociais segundo o grau em que garantem os direitos humanos universais. Permite o reconhecimento dos direitos universais e o estabel ecimento de uma hierarquia de prioridades.

\section{Resultados e discussão}

A tabela 1 apresenta os resultados gerais de classificação do nível de desenvolvimento moral dos entrevistados.

0 estágio 1, com menor nível de desenvolvimento moral, é geralmente percebido em crianças por volta de 7 a 8 anos de idade. Essa condição estabelece que juízos morais não necessitam de justificativa, e a simples aplicação de normas ou regras de forma absoluta ou literal respondem suficientemente a essas situações. Não leva em conta as circunstâncias que rodeiam a situação nem mediações fora das normas. N este estágio, a orientação ao castigo é bastante presente, com ações condicionadas pelo medo. Outra característica éa incapacidade de diferenciar perspectivas sócio-morais. $\mathrm{N}$ ão percebe $o$ conflito de interesses entre as partes envolvidas no dilema. Este indivíduo é incapaz de avaliar justiça em função de poder e status, o que o leva a considerar correta a submissão do forte ao fraco, sem a preocupação de alterar ou intercambiar estes papéis.

0 primeiro estágio é incompatível com o desenvolvimento almejado para profissionais de saúde, ainda mais na proporção observada de $16,66 \%$ dos entrevistados.

A maior parte dos entrevistados, 21 alunos (ou $50 \%$ da amostra), foi enquadrada no estágio dois de desenvolvimento moral. Um pouco além do primeiro estágio, o segundo estágio descobre interesses em conflito, porém coloca uma moralidade individualista e instrumental regulando esses interesses. Agora se percebe que as soluções unilaterais, baseadas na obediência a regras ou normas externas de maneira absoluta são inadequadas para resolver problemas do dia-a-dia. 0 sujeito no estágio dois percebe interesses próprios a cada indivíduo que podem não coincidir com os interesses de outros. Para resolver conflitos estas pessoas partem para um individualismo instrumental, ou seja, preconiza a troca de favores como explicação de suas ações (presta um favor a al-

\section{Quadro 1}

Classificação das normas.

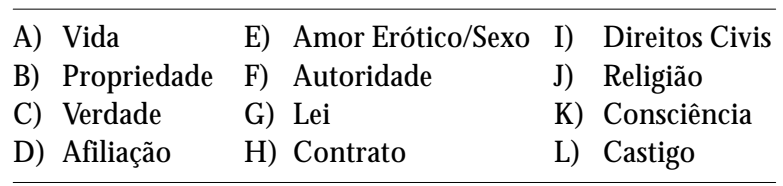

\section{Quadro 2}

Classificação dos elementos para classificação dos níveis de desenvolvimento moral.

\begin{tabular}{llll}
\hline A) Conseqüências egoístas & B) Conseqüências utilitaristas & C) Conseqüências ideais & D) Justiça \\
\hline Boa reputação & Boas conseqüências individuais & Proteger o caráter & Equilibrar perspectivas \\
Busca de recompensa & Boas conseqüências de grupo & Proteger o auto-respeito & Reciprocidade \\
& & Ajudar o ideal social & Manutenção da eqüidade \\
& & Ajudar a dignidade humana & Contrato social \\
\hline
\end{tabular}


Tabela 1

Classificação do nível de desenvolvimento moral de formandos do curso de $\mathrm{O}$ dontologia da UFSC, 2000.

\begin{tabular}{lcc}
\hline Nível & \multicolumn{2}{c}{ Freqüência } \\
& Absoluta & $\%$ \\
\hline 1 & 7 & 16,66 \\
2 & 21 & 50,00 \\
3 & 10 & 23,80 \\
4 & 4 & 9,52 \\
5 & - & - \\
Total & $\mathbf{4 2}$ & $\mathbf{1 0 0 , 0 0}$ \\
\hline
\end{tabular}

guém porque amanhã pode receber outro favor em troca) ou trata a todos de forma indiferenciada.

É necessário lembrar que esse estágio de de senvolvimento moral caracteriza crianças por volta de 10 ou 11 anos, efoi encontrado em metade dos formandos, que deverão cumprir padrões éticos e morais essenciais no seu trabaIho, mas que o farão na medida de seu interesse individual.

Dez acadêmicos, ou 23,8\% da amostra, foram classificados no estágio três, mostrando mai or capacidade de articular interesses individuais com uma perspectiva de terceiros. Supera-se assim o individualismo instrumental para construir um conjunto de normas ou expectativas morais compartilhadas que se espera que todos cumpram. Com isso, pode-se formar uma base para o estabelecimento de relações de confiança mútua que transcendem os interesses particulares. 0 sujeito nesse estágio está especialmente preocupado com relações interpessoais como forma de manter a confiança e a aprovação social. I mpera um paradigma de ser bom eajudar o próximo acima de tudo, em que o mais importante é cumprir as expectativas dos outros.

0 estágio três começa a se construir em torno de 12 ou 13 anos de idade e caracteriza o raciocínio da maioria dos adolescentes e adultos. Entretanto, ainda éum comportamento aquém do que se poderia esperar em profissionais de saúde por condizer com uma construção ainda estereotipada de conduta, podendo empobrecer em muito a relação do profissional de saúde com a comunidade.

0 maior estágio alcançado no estudo foi 0 quarto, com quatro indivíduos, o correspondente a 9,52\% da amostra. Agora o indivíduo se percebe na qualidade de membro da socie- dade, integrando expectativas interpessoais e as normas compartilhadas em um sistema mais amplo. N este estágio, o sujeito considera o sistema social um conjunto coerente de códigos e procedimentos que se aplicam imparcialmente a todos os seus membros. A busca de interesses individuais só se legitima se for coerente com a manutenção do sistema sócio-moral em seu conjunto. A estrutura social composta de um conjunto de relações e instituições tem 0 papel de mediar conflitos e promover o bem comum. A preocupação pela coerência e imparcialidade é bastante marcante nesse indivíduo, e sua prioridade é a manutenção do sistema social estabelecido e codificado por leis e práticas institucionalizadas mesmo que isso não coincida com os direitos humanos.

Apesar de o estágio quatro não abordar os conflitos do dia-a-dia a partir da moralidade dos direitos humanos e bem-estar social, de uma forma desvinculada de leis, regras, padrões e costumes - como propõe o estágio cinco de Aguado \& M edrano (1999) e no qual nenhum entrevistado foi classificado -, mostra-se como um estágio aceitável para dentistas.

Destaca-se que $90,46 \%$ dos entrevistados foram classificados em estágio menor ou igual a três. Este desenvolvimento moral está aquém do esperado para o pleno exercício da prática da saúde, pois os entrevistados se enquadram em um nível que não reconhece direitos e deveres recíprocos em um sistema social e não tem preocupações pela coerência e imparcialidade de suas ações.

0 estágio de desenvolvimento moral mais encontrado em adolescentes e adultos na população em geral é o estágio 3, segundo Aguado e M edrano (1999). No entanto, no grupo pesquisado o estágio mais freqüente foi o segundo, 0 que permite concluir que dois terços dos formandos têm um nível de desenvolvimento ético e moral não apenas aquém do almejado, mas aquém do nível da população em geral.

Some-se a isto o fato de se ter trabalhado o dilema mais diretamente relacionado aos profissionais da saúde, dentre diversos modelos propostos pelas autoras: o conflito vida $\mathrm{x}$ lei.

É questionável a atuação de um profissional da saúde que sustente sua conduta em ações individualistas, que age motivado pela troca de favores e não relativize as situações do cotidiano, características que se encaixam para 50\% dos formandos.

Tal constatação sugere - pressupondo que o perfil encontrado neste curso não seja essen- 
cialmente diferente de outros cursos no Brasil uma evidente inadequação da maior parte dos cirurgiões-dentistas para a prática da profissão pautada por valores morais, em termos éticose de responsabilidade social.

Identifica que um formando no nível 2 não está preparado para atuar no mercado de trabalho como profissional de saúde. Sua construção de valores encontra-se muito abaixo daquilo que a sociedade espera ou necessita.

As conseqüências dessa debilidade na formação podem ser desastrosas. O corre uma inversão de valores: a vida passa a ser secundária em relação ao interesse particular do indivíduo. Cotidianamente, o profissional encontrase diante de dilemas envolvendo os mais diversos val ores. Lidar com as contradições postas por eles e regular os interesses antagônicos sustentado pelo individualismo instrumental derivado da formação universitária torna-se potencialmente perigoso para a sociedade. Será que ele atenderá, em seu consultório, um paciente com dor, mesmo que este não possa pagar? Terá imparcialidade na fila, caso atue no SUS, ou priorizará seus "conhecidos"? Cumprirá seu horário no serviço público? Deixará de executar um procedimento mais demorado em um paciente por estar próximo do final de seu turno de trabalho? As respostas a estes e tantos outros apontamentos só poderão ser dadas, efetivamente, na prática dos entrevistados. No entanto, o estudo aponta para comportamentos preocupantes, com conseqüências que podem ser graves para a sociedade.

Não há como resolver questões de caráter coletivo ou individual quando a conduta moral do profissional é guiada por interesses particulares e visões unilaterais.

Esta inadequação deve servir de questionamento às práticas da universidade por não ter viabilizado que 0 acadêmico alcance um nível de desenvolvimento moral aceitável no final de seu curso. M ais grave ainda é o questionamento da responsabilidade que a universidade tem quando confere o título de cirurgião-dentista a alguém que jura cumprir padrões éticos e morais, mas não transcende o interesse individual envolvendo a vida humana.

Desse modo coloca-se em dúvida a existência, tanto no curso quanto na universidade, da real preocupação com a formação integral do aluno universitário, não apenas para o mercado, mas como membro de uma sociedade, um cidadão com a responsabilidade social de promover saúde. A formação ética deve integrar, como conteúdo transversal, os programas dos cursos universitários, de modo que o profissional "socialmente sensível" desejado pela profissão não se torne uma abstração. (Tabela 2)

Dos 42 acadêmicos entrevistados, doze escolheram o valor vida, enquanto 27 escolheram o val or lei e três ficaram indefinidos. Esses $64,27 \%$ que se direcionaram para o valor lei apresentam, portanto, uma percepção de moral que valoriza prioritariamente a lei como elemento maior de posicionamento diante da vida.

A partir do momento que estudantes, em especial da área da saúde, posicionam-se, em sua grande maioria, pelo cumprimento da lei em detrimento da vida humana, é preciso repensar profundamente quem estamos formando e se é este o recurso humano que se pretende integrar na sociedade.

É importante observar, também, que o somatório de indecisos e dos que apresentaram opção por um dilema apenas como ten dência resulta em $57 \%$ dos entrevistados, mostrando que há muitas dúvidas e indefinições nas suas decisões; a falta de uma formação moral transparece de maneira mais clara neste aspecto. M ais da metade dos alunos ingressará no mercado de trabal ho sem ter muita certeza de como pautar suas decisões profissionais a partir de valores morais.

A escolha das normas foi justificada majoritariamente sobre as normas de vida e lei. N as argumentações daqueles que já haviam escolhido a vida no dilema apresentado, em 12 vezes a justificativa dessa opção foi pela norma vida. As normas afiliação e consciência foram citadas apenas uma vez cada. Entre aqueles que optaram pela lei no dilema apresentado, a norma vida foi citada em 13 oportunidades, a norma

Tabela 2

Opção dos formandos do curso de Odontologia da UFSC, 2000, entre os dilemas lei/vida.

\begin{tabular}{lccc}
\hline Dilema & Envolvimento & \multicolumn{2}{c}{ Freqüência } \\
& & Absoluta & $\%$ \\
\hline vida & claramente & 7 & 16,67 \\
& tendência & 5 & 11,90 \\
\hline lei & claramente & 11 & 26,19 \\
& tendência & 16 & 38,10 \\
\hline indefinido & & 3 & 7,14 \\
\hline Total & & $\mathbf{4 2}$ & $\mathbf{1 0 0 , 0 0}$ \\
\hline
\end{tabular}


lei 14 vezes e outras normas mais sete vezes, como pode ser visto na tabela 3 .

Tal constatação demonstrou que os entrevistados atribuem à preservação da vida uma grande importância. 0 primeiro grupo (o que optou vida/vida) demonstrou coerência em suas justificativas, o que não necessariamente representa um bom nível de desenvolvimento moral, pois não foi citada a qualidade dessa vida ou a defesa da mesma como direito inalienável das pessoas acima dos interesses comerciais ou individuais, mas pura esimplesmente a vida pela vida ou por interesses utilitaristas. Já no segundo grupo (os que optaram pelo dilema lei) há 14 citações da norma lei, ou seja, a vida deve ser preservada, porém a defesa dela deve limitar-se ao permitido pela lei. (Tabela 4)

Verificar quais as motivações éticas que levaram o sujeito à sua opção por determinado dilema é de grande importância para poder-

\section{Tabela 3}

O pção dos formandos do curso de O dontologia da U FSC, 2000, entre as diferentes normas.

\begin{tabular}{lrcc}
\hline Normas & \multicolumn{3}{c}{ Freqüência } \\
& Lei & Vida & Indecisos \\
\hline (A) vida & 13 & 12 & 3 \\
(B) propriedade & 2 & - & - \\
(D) afiliação & 3 & 1 & - \\
(F) autoridade & 1 & - & 1 \\
(G) lei & 14 & - & 1 \\
(K) consciência & 1 & 1 & - \\
\hline
\end{tabular}

Obs: As normas não constantes na tabela acima não foram citadas. mos classificar o grau de desenvolvimento moral. No grupo que optou pelo dilema lei, o critério de juízo da conseqüência utilitarista individual foi o mais citado, com 33,33\%. M uito citados também foram: busca de recompensa, com $23,81 \%$; ea preservação da reputação, com $21,43 \%$.

No grupo que escolheu o dilema vida, os critérios mais citados não se alteraram, apenas sua distribuição. O CJ8 teve $64,29 \%$ das citações, o CJ 6 teve $11,9 \%$ e o CJ 7 teve $7,14 \%$. Constata-se que as ações que os entrevistados julgam corretas para o caso são motivadas por conseqüências utilitaristas e egoístas, não priorizando a justiça ou a harmonia social.

Esse elemento de análise torna-se preocupante, pois tal resultado mostra o despreparo do profissional de saúde em assumir seu papel de agente modificador da sociedade. Limitase a ações individualistas, por medo de prejuízo pessoal ou de abalar sua reputação, caracterizando um profissional com uma atuação sem compromisso social, sem tentar fazer valer eqüidade e justiça.

Assim, na formação do indivíduo, essa concepção do bem-estar de todos e da necessidade de promoção de saúde coletiva é substituída por interesses que se limitam a restituir o bemestar do indivíduo apenas daqueles que podem pagar. Este momento, que possivelmente é anterior a entrada do aluno no curso de odontologia, não é revertido pela formação odontológica, permitindo a manutenção de um modo de compreender a profissão e a própria vida com conseqüências prejudiciais à sociedade.

\section{Tabela 4}

Opção dos formandos do curso de O dontologia da UFSC - 2000, entre os diferentes critérios de juízo.

\begin{tabular}{lcccc}
\hline CJ & \multicolumn{2}{c}{ Lei } & \multicolumn{2}{c}{ Vida } \\
\hline & \multicolumn{2}{c}{ Freqüência } & \multicolumn{2}{c}{ Freqüência } \\
& absoluta & relativa & absoluta & relativa \\
\hline (6) boa reputação & 9 & 21,43 & 5 & 11,90 \\
(7) busca de recompensa & 10 & 23,81 & 3 & 7,14 \\
(8) boas conseqüências individuais & 14 & 33,33 & 27 & 64,29 \\
(9) boas conseqüências de grupo & 3 & 7,14 & - & - \\
(10) proteger o caráter & 1 & 2,38 & 1 & 2,38 \\
(11) proteger o auto-respeito & - & - & 1 & 2,38 \\
(12) ajudar a harmonia ou ideal social & - & - & 1 & 2,38 \\
(14) equilibrar perspectivas & 1 & 2,38 & - & - \\
ou adoção de caracteres & & & & \\
indecisos & 4 & 9,52 & 4 & 9,52 \\
\hline
\end{tabular}

Obs: Os valores não constantes acima não foram citados. 
Adotamos o pressuposto da OPS (Andrade, 1979), de que o marco conceitual da formação médica é definido por relações externas ao processo pedagógico, em que a influência da estrutura socioeconômica do país, sua estrutura de prática médica e a ideologia profissional são peças fundamentais para compreender este processo. No Brasil, o projeto pedagógico hegemônico para o ensino odontológico é fundamentado no modelo flexneriano, e classificado como científico ou tradicional por $M$ endes $\& M$ ar$\cos$ (1985).

Este modelo tradicional é o existente no curso de odontologia pesquisado e é criticado por diversos autores desde a década de 1980. PadiIha (1998) fez uma síntese destas críticas e classifica este model o como ineficiente, ineficaz, iatrogênico e sem eqüidade.

Diversos model os alternativos foram propostos, dos quais destaca-se o de Pires Filho (1995), que identifica três outros modelos de prática para além deste: o Inovado, o Preventivista e o Integral, dos quais o último explicita a necessidade de um dentista mais humanizado e ten do como objetivo a promoção da saúde, conforme proposta original de $M$ endes $\& M$ ar$\cos$ (1985). E o de Botazzo et al. (1988) que, sob outro enfoque, indicam o modelo de Saúde Bucal Coletiva, com a politização das causas da doença e sua vinculação às práticas coletivas de saúde, num distanciamento cada vez maior da odontologia tradicional e assumindo um objeto de trabal ho coletivo.

Em um modelo em que prevalecem a técni$c a$, a atenção individual e a ideologia liberal da profissão, o desenvolvimento moral encontrado não é surpreendente, mas esperado. Os conceitos que os estudantes de odontologia trazem podem ser mantidos ou reforçados durante 0 desenvolvimento do curso, mas dificilmente serão reformulados. É esta discussão que deve ser reaberta para os projetos pedagógicos que pretendam reformular a formação odontológica em busca do profissional que já é tecnicamente capaz, mas nunca foi socialmente sensível.

\section{Conclusões}

1. O nível de desenvolvimento moral encontrado entre os formandos é baixo, e menor do que o esperado para adultos;

2. este nível é inadequado para o exercício da profissão, pois interfere nas relações éticas do cotidiano;

3. o curso de odontologia não consegue viabilizar este desenvolvimento moral desejável;

4. este nível pode acarretar conseqüências danosas para o futuro profissional, para os pacientes e para a sociedade.

\section{Colaboradores}

SFT Freitas propôs o tema, orientou o estudo e foi responsável pela redação final do texto. DF Kovaleski e AF Boing aplicaram as entrevistas, analisaram os resultados e redigiram 0 artigo 


\section{Referências bibliográficas}

Aguado MJD \& M edrano C 1999. Construção moral e educação. EDUSC, Bauru.

Andrade J 1979. M arco conceptual de la educación médica en la America Latina. OPS, Washington. (Série Desarrollo de Recursos Humanos, n. 28).

Botazzo C et al. 1988. Saúde bucal coletiva. Instituto de Saúde, São Paulo.

Cordón JAP 1977. Consideraciones sobre "simplificación" en odontología. Rev. CERÓN 2(1):8-9.

Cordón JAP 1982 Prevención y racionalización en estomatología. Rev. CERÓN 7(2):2-3.

Cordón JAP \& Silva HO 1980. Las categorías “monopolio" y "desmonopolización" en estomatología. Acta Odón. Venezolana 18(3):419-38.

Kohlberg L 1958. The development of modes moral thinking in the years ten to sixteen. University of Chicago, Chicago.

Kohlberg L 1984. The psychology of moral development., H arper and Row, São Francisco.

Kohlberg L 1999. Continuites in childhood and adult moral development revisited, N ew York, 1973, pp. 3833. In MJD Aguado \& C M edrano. Construção moral e educação. EDUSC, Bauru.
M endes EV \& M arcos B 1985. O dontologia integral: bases teóricas e suas implicações no ensino e na pesquisa odontológica. FUMARC - PUC/M G, Belo Horizonte.

Padilha WWN 1998. Análise da situação da disciplina de clínica integrada nos cursos de graduação em odontologia: evolução, modelo pedagógico e enfoque curricular. Tese de doutorado. FO/USP, São Paulo.

Paixão H H 1981. O paciente como objeto de ensino. Arq. Cent. Est. Univ. Fed. M inas Gerais 18(1-2):37-40.

Piaget J 1972. Intellectual evolution from adolescence to adulthood. Human Development 15:1-12.

Pires Filho FM 1995. A construção interativa do saber e do fazer acadêmicos: o desafio da prática odontológica integral. Tese de doutorado. UFF, Niterói. (tese)

Artigo apresentado em 22/03/2004

Aprovado em 5/05/2004

Versão final apresentada em 5/09/2004 